\title{
Perspective on the future approaches to predict retention in liquid chromatography
}

\author{
Fabrice Gritti* \\ Waters Corporation, 34 Maple Street \\ Milford, MA 01757, USA
}

SUPPLEMENTARY MATERIALS

*Corresponding author: (E-mail) Fabrice_Gritti@waters.com; (Tel) 508-482-2311; (Fax) 508-482-2625. 


\section{${ }_{5} 1$ Conventional determination of the hold-up volume of LC columns}

In practice, the mobile phase volume, $V_{0}$, is most often measured dynamically from the elution time, $t_{\text {marker }}$, of a "non-retained" marker. Still, the practitioner has no clue whether such markers neither slightly accumulates into nor is partially excluded from the interfacial region. So, the arbitrary measurement of the hold-up volume is obtained from:

$$
V_{0}=F_{v} t_{\text {marker }}
$$

where $F_{v}$ is the applied flow rate.

$V_{0}$ can also be measured dynamically from the retention times of a series of homologous compounds. In RPLC, a well-known linear relationship was proposed ${ }^{1}$ :

$$
\ln \left(F_{v} t_{R, n}-V_{0}\right)=a n+b
$$

where $t_{R, n}$ is the experimental retention time of the homologous compound containing $n$ carbons. $a, b$, and $V_{0}$ are then estimated from the best fit of Eq. 2 to the experimental data.

Finally, $V_{0}$ can be measured from static methods such as the pycnometry method in which two different fluids 1 and 2 having significantly different densities are used to fill the column ${ }^{1,2}$. Accordingly,

$$
V_{0}=\frac{m_{1}-m_{2}}{\rho_{1}-\rho_{2}}
$$

where $m_{1}$ and $m_{2}$ are the weights of the column filled with the fluids 1 and 2 , respectively. $\rho_{1}$ and $\rho_{2}$ are their corresponding densities. For instance, air (density $1.184 \mathrm{~kg} / \mathrm{m}^{3}$ at $25^{\circ} \mathrm{C}$ ) and dichloromethane (density $1325 \mathrm{~kg} / \mathrm{m}^{3}$ at $25^{\circ} \mathrm{C}$ ) are an excellent choice for this pair of fluids.

All the above methods have their own advantages and disadvantages as discussed in previous reports ${ }^{1-3}$. In conclusion, there are as many volumes $V_{0}$ as methods used to measure the column hold-up volume. The measured conventional retention factors $k_{\text {conv }}$ can then be inconsistent among laboratories and is inevitably different from the true and correct retention factor. 


\section{Retention prediction based on curved retention models}

The curved Neue-Kuss retention model is derived for linear gradient ${ }^{4-6}$ and is written:

$$
t_{R, g}=t_{0}+t_{D}+\frac{1}{S \beta} \frac{\left(1+a \varphi_{0}\right)^{2} \ln \left(1+S \beta k_{0} \exp \left[-\frac{S \varphi_{0}}{1+a \varphi_{0}}\right]\left[t_{0}-\frac{t_{D}}{k(0)}\right]\right)}{1-a \frac{1+a \varphi_{0}}{S} \ln \left(1+S \beta k_{0} \exp \left[-\frac{S \varphi_{0}}{1+a \varphi_{0}}\right]\left[t_{0}-\frac{t_{D}}{k(0)}\right]\right)}
$$

where $t_{0}$ is the hold-up time of the column, $t_{D}$ is the dwell time of the LC instrument, $\varphi_{0}$ is the volume fraction of the strong solvent at the beginning of the gradient, $\beta$ is the gradient slope, and $k(0)$ is the retention factor of the analyte at the beginning of the gradient. $k_{0}, a$, and $c$ are the three parameters of the Neue-Kuss retention model to be determined by a standard fitting procedure.

\section{Gradient recycling chromatography}

Gradient recycling process is based on the use of a 6-port 2-position valve, a 4-port 2-position valve, and two twin columns. Its principle and sequence of events are described and illustrated in Figures S1-S8. The switch of the 4-port 2-position valve allows to transfer of the targeted elution zone (containing the targeted compound and two nearly co-eluting impurities) from one twin column (used to clean the complex sample mixture for most early and late impurities by running a steep gradient) to the second twin column (primarily equilibrated with the mobile phase used in a classical isocratic recycling process $\left.{ }^{7-11}\right)$. The targeted sample zone transferred and parked in the inlet region of the second twin column contains increasing amounts of strong solvent as set by the programmed gradient. This should be taken into account for the prediction of both the elution times (at any fixed location) and the locations (at any fixed time) of the targeted compound and close impurities during the recycling process. The switch of the 6-port 2-position valve enables the transfer of the targeted elution zone from one to the second twin column (and vice versa) as previously described in ${ }^{7-11}$. The goal is to collect pure fractions of the targeted compound after a sufficiently large number of recycling steps allowing to baseline separate the band of the targeted compound from those of the two closest impurities (one impurity elutes immediately before the target compound, the second one immediately after). 
The recycling technique was applied for the isolation and separation of vitamins D2 and D3 present in milk-based nutritionals starting with a gradient cleaning step (strong solvent: methanol) followed by a certain number of isocratic recycling steps. The sample volume injected is $300 \mu \mathrm{L}$. The starting volume fraction of methanol is $\varphi_{\text {cleaning,start }}=0.923$ (the final volume fraction of methanol is 1 ) and the gradient time is $t_{g, c l e a n i n g}=10.33 \mathrm{~min}$. The volume fraction of acetonitrile in water during the isocratic recycling is $\varphi_{\text {recyling }}=0.987$. 14 cycles are predicted to be necessary for the baseline resolution of vitamins D2 and D3. All the programmed switching times of the four- and sixport valves are listed in Table S2. Figure S9 shows the corresponding experimental chromatogram confirming the expected successful isolation and baseline separation of vitamins $\mathrm{D}_{2}$ and $D_{3}$ after gradient cleaning and 14 cycles for the recycling process.

\section{Retention models in mixed-mode chromatography}

The elementary models of retention in liquid chromatography are given by:

1- For the effect of the volume fraction, $\varphi$, of the strong eluent in RPLC, the LSS model is often used $^{12}$ :

$$
\ln k=\ln k(0)-S \varphi
$$

where $k(0)$ is the extrapolated retention factor in pure water and $S$ is an empirical parameter. In practice, the experimental plots of $\ln k$ versus $\varphi$ are rarely strictly linear, so, the quadratic 13 or curved Neue-Kuss ${ }^{4,5}$ retention models have been proposed after introduction of a third model parameter.

2- For the effect of the volume fraction, $\varphi_{\mathrm{H}_{2} \mathrm{O}}$, of water in HILIC, the following model has been proposed :

$$
k=\left(b+a \varphi_{H_{2} O}\right)^{-m}
$$

where $a, b$, and $m$ are empirical parameters.

3- For the effect of temperature $T$ and pressure $P$ on retention, this retention model is used 
14,15 :

$$
\ln k=\ln k_{0}-\frac{Q_{s t}}{R T}-\frac{\Delta V_{m}}{R T}\left(P-P_{r e f}\right)
$$

where $Q_{s t}$ is the isosteric heat of adsorption, $\Delta V_{m}$ is the change in partial molar volume of the analyte between the stationary and mobile phases, $R$ is the molar gas constant $(8.31$ $\mathrm{J} / \mathrm{K} / \mathrm{mol}), P_{r e f}$ is a reference pressure, and $k_{0}$ is the extrapolated retention factor at infinitely high temperatures.

4- For the effect of pure electrostatic interactions (ex: anion exchange or AEX) on retention, the following model is used to predict the retention factor of permanently and negatively charged analytes as a function of $\mathrm{pH}$ and anion bulk concentration $[A-]^{16,17}$ :

$$
k=\frac{1}{[A-]} \frac{k_{0, A E X}}{1+10^{p H-p K_{a}}}
$$

where $k_{0, A E X}$ is an empirical parameter and $p K_{a}$ is the dissociation constant of the AEX surface ligand which is discharged at $\mathrm{pH} \gg \mathrm{pK}_{a}$.

The RP/IEX MMC model of Stahlberg model is written ${ }^{18,19}$ :

$$
k_{R P / I E X}=k_{0, R P} \exp \left(-S_{R P} \varphi\right) \exp \left[-\frac{z_{A} z_{I E X} F \sigma_{A E X}}{\kappa \epsilon_{r} \epsilon_{0} R T} \frac{I_{0}\left(\kappa r_{p}\right)}{I_{1}\left(\kappa r_{p}\right)}\right]
$$

where $k_{0, R P}$ is the retention factor in pure water and in absence of surface charge, $z_{A}$ is the charge number of a permanently charged analyte, $z_{I E X}$ is the charge number of the permanently charged IEX ligand, $F$ is the Faraday constant $(96500 \mathrm{C} / \mathrm{mol}), \sigma_{A E X}$ is the surface concentration of the AEX ligand $\left(\mathrm{mol} / \mathrm{m}^{2}\right), \epsilon_{r} \epsilon_{0}$ is the permittivity of the bulk phase $\left(\epsilon_{0}=8.85 \times 10^{12} \mathrm{~J}^{1} \mathrm{C}^{2} \mathrm{~m}^{1}, \epsilon_{r}\right.$ is the relative permeability of the bulk phase), $R$ is the molar gas constant $(8.31 \mathrm{~J} / \mathrm{K} / \mathrm{mol}), T$ is the absolute temperature expressed in Kelvin, $I_{0}$ and $I_{1}$ are the modified Bessel functions of the first kind of order 0 and 1 , respectively, $r_{p}$ is the pore radius and $\kappa\left(\mathrm{m}^{-1}\right)$ is the Debye inverse length defined as:

$$
\kappa=F \sqrt{\frac{2 I}{\epsilon_{r} \epsilon_{0} R T}}
$$


. where $I$ is the ionic strength of the eluent.

$$
I=\frac{1}{2} \sum_{i} c_{i} z_{i}^{2}
$$

where $c_{i}$ is the concentration of all ions and $z_{i}$ is the charge number of ion $i$.

Stahlberg's model Eq. 13 can be extended to cases where both the IEX ligand and the analyte are not permanently charged depending on the applied $\mathrm{pH}$. In addition to its dependence on the concentration of the strong solvent and ionic strength of the mobile phase, $k_{R P / I E X}$ then also becomes a function of the applied $\mathrm{pH}^{17}$. The molar fractions, $f_{I E X a}$ and $f_{I E X b}\left(f_{I E X a}+f_{I E X b}=1\right)$, of the acidic $\left(z_{I E X a}\right.$ charge number $)$ and basic $\left(z_{I E X b}=z_{I E X a}-1\right)$ ligand species, respectively, is given by:

$$
p H=p K_{a, I E X}+\log \frac{f_{I E X b}}{f_{I E X a}}
$$

where $p K_{a, I E X}$ is the $\mathrm{pK}_{a}$ of the IEX ligand.

Additionally, the analyte can exist in solution as two different species depending on $\mathrm{pH}$. From Eq. 13, the general expression of the equilibrium constant $K_{R P / I E X}$ for an acido-basic analyte (acidic species $A$ with charge $z_{A}$, basic species $B$ with charge $z_{B}=z_{A}-1, \mathrm{pK}_{\text {a,analyte }}$ ) and a non-permanently charge IEX ligand $\left(\mathrm{pK}_{a, I E X}\right)$ is then written:

$$
\begin{aligned}
& K_{R P / I E X}=\frac{1}{1+10^{p H-p K_{a, \text { analyte }}}} K_{0, R P, A} \exp \left(-S_{R P, A} \varphi\right) e^{\left[-\frac{z_{A}\left(z_{I E X a}+z_{I E X} 10^{\left.p H-p K_{a, I E X}\right) \sigma_{I E X} F} \frac{I_{0}\left(\kappa r_{p}\right)}{I_{1}\left(\kappa r_{p}\right)}\right.}{\left(1+10^{\left.p H-p K_{a, I E X}\right) \kappa \epsilon_{r} \epsilon_{0} R T}\right.}\right.} \\
& +\frac{10^{p H-p K_{a, \text { analyte }}}}{1+10^{p H-p K_{a, \text { analyte }}}} K_{0, R P, B} \exp \left(-S_{R P, B} \varphi\right) e^{\left.\left[-\frac{z_{B}\left(z_{I E X a}+z_{I E X b} 10^{\left.p H-p K_{a, I E X}\right) \sigma_{I E X} F}\right.}{\left(1+10^{p H-p K_{a, I E X}\left(\kappa r_{p}\right)}\right.}\right)^{I_{1}\left(\kappa \epsilon_{r} \epsilon_{0} R T\right.}\right]}
\end{aligned}
$$

Note that the above retention model can be extended to cases where the analyte has multiple pKa and the adsorbent surface is populated with multiple AEX and CEX ligands with their respective $\mathrm{pK}_{a, A E X}$ and $\mathrm{pK}_{a, C E X}$ values. Such hybrid retention models can easily be tested and implemented in current commercial software used for method development. They could potentially provide a better description of the complex retention mechanism observed in mixed-mode chromatography. A few examples regarding the applications and the limits of the retention model Eq. 13 are given below for the Atlantis Premier BEH-C 18 AX MMC column. 


\section{Retention prediction of procainamide in MMC}

The two $\mathrm{pK}_{a} \mathrm{~s}$ of procainamide are $\mathrm{pK}_{a, 1}=2.78$ and $\mathrm{pK}_{a, 2}=9.32^{20}$. The predominant species below $\mathrm{pH} 2.8$, in the $\mathrm{pH}$ range from 2.8 and 9.3 , and above $\mathrm{pH} 9.3$ are the two times positively charged species $\mathrm{A}\left(z_{A}=+2\right)$, the single positively charged species $\mathrm{B}\left(z_{B}=+1\right)$, and neutral basic species $\mathrm{C}$ $\left(z_{C}=0\right)$, respectively. The retention factors of procainamide were measured on the same MMC column as that above-mentioned (see the open red circles in Figure S10) from pH 2.5 to 8.0. The same experimental conditions as those used for the elution of adenosine 5'-monophosphate were applied. $\mathrm{pK}_{a, A E X}$ was fixed at 8.50 based on the best results obtained in the previous section. Accordingly, the best estimated RP equilibrium constants are listed in Table 1 and the best model prediction is shown as the solid red line in Figure S10. The agreement between experimental and calculated retention factors is very good. As expected, the RP equilibrium constants are increasing from $K_{0, R P, A} \sim 0$ to $K_{0, R P, B} \sim 4.5 \times 10^{2}$ and to $K_{0, R P, C} \sim 1.8 \times 10^{3}$ with decreasing the charge of the procainamide from +2 to +1 and to 0 , respectively. The simultaneous increase of the dispersive interaction and decrease of the electrostatic repulsion between the positively charged species and the alkylamine ligand lead to a steady increase of procainamide retention when increasing $\mathrm{pH}$ from 2.5 to 8 . Again, the variation of the retention factor with increasing the ionic strength from 10 to $50 \mathrm{mM}$ at $\mathrm{pH} 3$ is not properly accounted for by the proposed model as shown in the right graph in Figure S11. This opens up important perspectives on the study of the retention mechanism of ionizable compounds by molecular dynamics simulation in order to refine and correct the proposed retention model.

\section{Convention for the measurement of the true strong solvent ad- sorption}

For binary acetonitrile-water plateau mixtures (the volume fraction of acetonitrile in the bulk is called $x$ ), the unique excess number of moles, $n^{e}(x)$, of adsorbed acetonitrile is unambiguously 
measured by the minor disturbance method (MDM) ${ }^{21-23}$ :

$$
n^{e}(x)=\frac{1}{v^{*}} \int_{0}^{x}\left[V_{R}(u)-V_{M}\right] d u
$$

where $V_{R}(u)$ is the measured elution volume of the infinitesimal perturbation on a plateau of composition $u$. $v^{*}$ is the molar volume of pure acetonitrile $\left(52.8 \mathrm{~cm}^{3} / \mathrm{mol}\right)$ and $u$ is a dummy integration variable. In general, the measurement of $n^{e}(x)$ assumes that that the contraction volume upon mixing of the two solvents is negligible (less than $2 \%$ and $4 \%$ for acetonitrile and methanol ${ }^{24}$, respectively), so, $x$ can be directly taken as the volume fraction of the strong solvent set by the instrument before mixing.

The concentrations $C(x)$ and $q(x)$ of acetonitrile in the mobile (volume $V_{M}$ ) and stationary (volume $V_{C}-V_{M}$ ) phases, respectively, are then ${ }^{25}$ :

$$
C(x)=\frac{x}{v^{*}} \quad \mathrm{~mol} / \mathrm{cm}^{3}
$$

and

$$
q(x)=\frac{n^{e}(x)}{V_{C}-V_{M}} \quad \mathrm{~mol} / \mathrm{cm}^{3}
$$

where $V_{C}$ is the volume of the empty column tube.

The plot of $q(x)$ versus $C(x)$ is the adsorption isotherm of the strong solvent. This isotherm is needed to account for the possible retention and distortion of the linear gradients applied to the column inlet. This happens when the gradient starts with water-rich and acetonitrile-rich eluents in RPLC and HILIC, respectively, and when the ratio of the gradient volume to the hold-up volume is smaller than about $3^{25}$. This considerably affects the retention and the resolution of critical pairs of compounds by gradient elution 26,27 . 


\section{Convention for the measurement of the true system dwell vol- ume}

In absence of column, the recorded plot of the system pressure as a function of time $(t=0$ when the gradient starts) is recorded. The time $t_{1 / 2}$ at which the system pressure is measured at half the sum of the starting (with $75 \%$ acetonitrile in water) and final (with $55 \%$ acetonitrile in water) system pressure is unambiguously measured. The dwell volume of the instrument is then accurately given by:

$$
V_{d w e l l}=F_{v} t_{1 / 2}
$$

If the column has to stay in place, a linear gradient of acetonitrile from $75 \%$ to $55 \%(\mathrm{v} / \mathrm{v})$ at $T=27^{\circ} \mathrm{C}$ should be applied during $t_{g} \sim 3 \frac{V_{M}}{F_{v}}$. Similarly, the dwell volume of the instrument is accurately given by:

$$
V_{\text {dwell }}=F_{v}\left(t_{1 / 2}-\frac{\frac{V_{M}}{F_{v}}+t_{g}}{2}\right)
$$

\section{Mathematical description of the observed gradient profile at the column inlet}

The analytical expression of the convolution of a linear gradient ramp $(R(t))$ with an exponentially modified Gaussian $(E M G(t))$ function, $\varphi(t)=R(t) * E M G(t)$, is given by ${ }^{28}$ :

$$
\varphi(t)=\frac{1}{2} \beta[A(t)+B(t)+C(t)+D(t)]
$$


where

$$
\begin{aligned}
& A(t)=\sqrt{\frac{2}{\pi} \sigma}\left[e^{-\frac{\left[t-t_{D}\right]^{2}}{2 \sigma^{2}}}-e^{\frac{\left[t+t_{g}-t_{D}\right]^{2}}{2 \sigma^{2}}}\right] \\
& B(t)=\left(t-t_{D}-t_{g}\right) \operatorname{Erfc}\left[\frac{t_{D}-t}{\sqrt{2} \sigma}\right] \\
& C(t)=\left(t_{g}+t_{D}+\tau-t\right) \operatorname{Erfc}\left[\frac{t_{D}+t_{g}-t}{\sqrt{2} \sigma}\right] \\
& D(t)=e^{\frac{\sigma^{2}+2 \tau\left(t_{D}-t\right)}{2 \tau^{2}}} \tau\left[\operatorname{Erfc}\left(\frac{\sigma^{2}+\tau\left[t_{D}-t\right]}{\sqrt{2} \sigma \tau}\right)-e^{\frac{t_{g}}{\tau}} \operatorname{Erfc}\left(\frac{\sigma^{2}+\tau\left[t_{D}+t_{g}-t\right]}{\sqrt{2} \sigma \tau}\right)\right]
\end{aligned}
$$

where Erfc is complementary error function.

For the sake of illustration, the impact of the dwell volume of the Arc LC system (including the volumes of the gradient proportioning valve or GPV, the $132 \mu \mathrm{L}$ full stroke volume of both the primary and accumulator pump heads, a $675 \mu \mathrm{L}$ packed bead column mixer, the injector, and many large i.d. connecting tubes) on the deformation of the programmed linear gradient was investigated at five distinct flow rates $(0.25,0.50,1.00,2.00$ and $4.00 \mathrm{~mL} / \mathrm{min})$ and for a fixed gradient time $t_{g}=4 \mathrm{~min}$. Figure S12 (flow rates of 4 and $2 \mathrm{~mL} / \mathrm{min}$ ) and $\mathrm{S} 14$ (flow rates of 1.0 and $0.25 \mathrm{~mL} / \mathrm{min}$ ) reports the gradient profiles at different flow rates. The total geometric dwell volume was measured at $V_{D}=1.08 \mathrm{~mL}\left(t_{D}=\frac{V_{D}}{F_{v}}\right)$ based on the convention described in section 7 and used for the measurement of the dwell volume. The gradient starts at $t=1 \mathrm{~min}$ and the volume fraction of solvent B (a $0.05 \mathrm{~g} / \mathrm{L}$ solution of caffeine in water) in solvent A (pure water) increases from 0 to 1 , so, $\beta=0.25 \mathrm{~min}^{-1}$. The dashed black segments in Figure 5, S12, and S13 show the ideal and expected gradient profile in absence of gradient dispersion $(\sigma=0)$ and asymmetry $(\tau=0)$ between the GPV and the column inlet. The open blue circles represent the observed and dispersed gradient profiles (caffeine was detected at a wavelength of $272 \mathrm{~nm}$ ). The thin solid green line is the convoluted function (Eq. 21) that fits the best the recorded gradient profile. The best volume parameters, $\sigma F_{v}$ and $\tau F_{v}$, of the model are compared to the gradient volume $V_{g}$ and are given in the graph insert. The agreement between observed and calculated gradient profiles is excellent which confirms that Eq. 21 can describe accurately the observed gradient profiles at the column inlet. Remarkably, the time shift of the observed gradient profile relative to the ideal programmed 
gradient profile is increasing with decreasing the gradient volume, $V_{g}=F_{v} t_{g}$, from 16 to $8,4,2$, and to $1 \mathrm{~mL}$. This is explained by the fact that both the volume-based standard deviation $\sigma F_{v}$ (average $0.33 \mathrm{~mL}$ ) and the relaxation volume $\tau F_{v}$ (average $0.35 \mathrm{~mL}$ ) are no longer negligible relative to the gradient volume. It is then recommended that the two ratios, $\frac{\sigma}{t_{g}}$ and $\frac{\tau}{t_{g}}$, are both kept below $1 \%$ in order for the observed gradient profile to match quasi-perfectly the programmed one. If these conditions cannot be met in practice, the accurate prediction of the gradient retention times should require an accurate description of the true gradient profile observed at the column inlet. It can be measured following the above-mentioned protocol and be represented accurately by a mathematical model such as the proposed convolution of a ramp with an EMG function (Eq. 21).

Figure S12 (flow rates of 4 and $2 \mathrm{~mL} / \mathrm{min}$ ) and $\mathrm{S} 12$ (flow rates of 1.0 and $0.25 \mathrm{~mL} / \mathrm{min}$ ) reports on the gradient profiles at intermediate flow rates. The total geometric dwell volume was measured at $V_{D}=1.08 \mathrm{~mL}\left(t_{D}=\frac{V_{D}}{F_{v}}\right)$ based on the convention used for the measurement of the dwell volume. The gradient starts at $t=1 \mathrm{~min}$ and the volume fraction of solvent B (a $0.05 \mathrm{~g} / \mathrm{L}$ solution of caffeine in water) in solvent $\mathrm{A}$ (pure water) increases from 0 to 1 , so, $\beta=0.25 \mathrm{~min}^{-1}$.

\section{$9 \quad$ Linear solvation energy relationship}

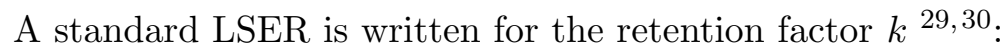

$$
\log k=\log k_{0}+v V_{2}+s \pi_{2}^{*}+a \sum \alpha_{2}^{H}+b \sum \beta_{2}^{H}+r R_{2}
$$

where $V_{2}, \pi_{2}^{*}, \sum \alpha_{2}^{H}, \sum \beta_{2}^{H}$, and $R_{2}$ are the most relevant molecular descriptors of the analyte including its molar volume, dipolarity/polarizability, overall hydrogen-bond acidity, overall hydrogenbond basicity, and excess molar refraction, respectively. The coefficients $\log k_{0}, v, s, a, b$, and $r$ are the best empirical parameters that characterize a pair of stationary and mobile phases. 


\section{Retention prediction by molecular dynamics: a four steps pro- cess}

\subsection{Step 1: building up the most representative simulation box}

MD simulations can be used to support the prediction of the retention factor in liquid-solid adsorption provided a most representative simulation box of the equilibrium system can be built. Typically, either rectangular (the distance between the faces is then equal to the average pore diameter) or cylindrical (the diameter is then equal to the average pore diameter) simulation box can be designed. The box should include 1) the surface of the solid silica layer usually taken as the (111) face of $\beta$-cristobalite (preferred crystalline model for the amorphous structure of chromatographic silica) with a silanol surface concentration of $7.5 \mu \mathrm{mol} / \mathrm{m}^{2}{ }^{31}, 2$ ) the attached ligands (in RPLC: $\mathrm{C}_{18}, \mathrm{C}_{8}$, endcapping agent, etc.) to the silica surface with the same surface coverage as those measured by elemental analysis, 3) the residual free and isolated silanols present at the silica surface with the same surface concentrations as those determined experimentally by ${ }^{29} \mathrm{CP} / \mathrm{MAS}$ NMR ${ }^{32-35}$ ), and 4) the correct numbers of solvent molecules introduced in the box so that they match the density of the bulk mobile phase at equilibrium ${ }^{31}$.

\subsection{Step 2: selection of the most relevant force fields}

Typical FFs for the neutral alkyl-bonded ligands and for the analytes is the transferable potentials for phase equilibria united-atom (TraPPE-UA) ${ }^{36-38}$. For the solvent molecules such as water and acetonitrile, the simple point charge/extended (SPC/E) and the TraPPr-UA force field, respectively, are used ${ }^{39,40}$. The particular force field of the Si, O, and $\mathrm{H}$ atoms of the solid silica are taken from the modified interaction potential of Gulmen and Thompson ${ }^{41}$. Interestingly, there is no literature about the study of the LC retention mechanism by MD simulations when charged ligands, salts, buffers, and ionizable analytes are involved. In the solid state, the parametrized FFs are usually combined with methods of assigning point charges to the atoms in the solid structure. Still, the vast majority of such methods are found not reliable to predict absolute lattice energies in crystal structures but a few like the polymer consistent force field with integral charges appeared accurate 
enough ${ }^{42}$. Overall, finding a relevant $\mathrm{FF}$ for the study of the equilibrium between a charged surface and a bulk phase containing salts, buffers, and ionizable analytes is definitely more challenging than selecting a reliable FF for neutral systems. This constitutes an important and future research avenue towards the accurate modeling of the retention mechanism of most ionizable compounds and impurities in the pharmaceutical, food, and biological industries.

\subsection{Step 3: determination of the equilibrium excess amount of analyte in the simulation box}

In a preliminary step, the Newton's equations of motion are solved numerically during about 1 $\mu \mathrm{s}$ (time step of $1 \mathrm{fs}$ ) for an NPT ensemble (constant temperature $T$, simulation box volume $V$, and pressure $P$ ) so that the density of the bulk mobile phase (far enough from the surface) is matching within $1 \%$ the targeted and experimental eluent density. The number of eluent molecules are manually adjusted between two successive simulation runs until the density match is reached ${ }^{31}$. The thermodynamic dead volume, $V_{p, M}$, of the simulation box is then calculated from the fraction of the box volume occupied by the eluent molecules.

In a second step, a negligible number of analyte molecules is introduced into the simulation box (typically 1 analyte molecule for about a few thousands eluent molecules) and the equations of motion are solved for a canonical NVT ensemble (constant temperature $T$, simulation box volume $V$, and number of molecules $N$ ). A sufficiently large number of system configurations are generated during the $1 \mu$ s run to enable the calculation of the equilibrium density profile, $\rho_{\text {analyte }}(z)$, of the analyte molecules as a function of the distance $z$ from the solid surface ${ }^{43}$. In particular the density

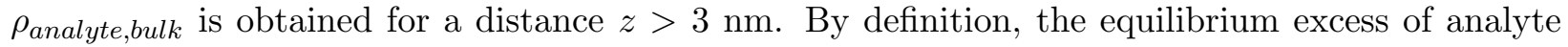
molecules $n_{\text {analyte,excess }}$ in a single simulation box is then computed by:

$$
n_{\text {analyte,excess }}=\int_{0}^{r_{\text {pore }}} \rho_{\text {analyte }}(z) S(z) d z-\rho_{\text {analyte }, \text { bulk }} V_{p, M}
$$

where $r_{\text {pore }}$ is the pore radius and $S(z)$ is the cross section area normal to the $z$-axis at a distance $z$ from the solid surface. $S(z)$ is independent of $z$ and $S(z)=2 \pi\left(r_{\text {pore }}-z\right)$ for rectangular and cylindrical simulation boxes, respectively. 


\subsection{Step 4: Calculation of the true retention factor}

Let us consider a chromatographic column packed with particles having the surface chemistry and the average pore size mimicked in the MD simulations and a target analyte of known molecular structure. Its thermodynamic void volume is $V_{M}$ and it develops an unknown total silica surface $S_{\text {silica }}=N_{\text {pore }} S(0)$, where $N_{\text {pore }}$ is the total number of pores in the column. By definition, the true retention factor, $k_{t r u e, M D}$, calculated from MD simulations is given by:

$$
k_{\text {true }, M D}=\frac{N_{\text {pore }}}{V_{M}} \frac{n_{\text {excess }, \text { tar }}}{\rho_{\text {excess }, \text { tar }}}
$$

where the ratio $\frac{N_{\text {pore }}}{V_{M}}$ is the unknown phase ratio of the column, $n_{\text {excess,tar }}$ is the equilibrium excess of the target analyte molecule in a single simulation box, and $\rho_{\text {excess,tar }}$ is its equilibrium density profile in the bulk phase.

The phase ratio can be determined by measuring the retention factor, $k_{t r u e, r e f}$, of a reference and retained analyte molecule (ex: toluene in RPLC or p-dihydroxybenzene in HILIC) and by calculating from MD simulations its equilibrium excess, $n_{\text {excess,ref }}$, and its bulk density, $\rho_{\text {excess,ref }}$. Accordingly,

$$
\frac{N_{\text {pore }}}{V_{M}}=k_{\text {true }, \text { ref }} \frac{\rho_{\text {excess,ref }}}{n_{\text {excess,ref }}}
$$


${ }_{269} 11$ Supplementary Tables 
Table S1 : Programmed times for the valve switches (chrysene)

\begin{tabular}{|c|c|c|c|}
\hline Time [min] & Four-port valve position & Six-port valve position & Cycle number \\
\hline 3.63 & 1 & 1 & Transfer starts \\
\hline 4.60 & 2 & 1 & Transfer ends \\
\hline 7.78 & 1 & 1 & Recycling starts \\
\hline 7.78 & 1 & 2 & 1 \\
\hline 15.02 & 1 & 1 & 2 \\
\hline 20.39 & 1 & 2 & 3 \\
\hline 25.76 & 1 & 1 & 4 \\
\hline 31.13 & 1 & 2 & 5 \\
\hline 36.50 & 1 & 1 & 6 \\
\hline 41.87 & 1 & 2 & 7 \\
\hline 47.24 & 1 & 1 & 8 \\
\hline 52.61 & 1 & 2 & 9 \\
\hline 57.98 & 1 & 1 & 10 \\
\hline 63.35 & 1 & 2 & 11 \\
\hline 68.72 & 1 & 1 & 12 \\
\hline 74.09 & 1 & 2 & 13 \\
\hline 79.46 & 1 & 1 & 14 \\
\hline 84.83 & 1 & 2 & 15 \\
\hline 90.20 & 1 & 1 & 16 \\
\hline 95.57 & 1 & 2 & 17 \\
\hline 100.94 & 1 & 1 & 18 \\
\hline 106.31 & 1 & 2 & 19 \\
\hline 111.68 & 1 & 1 & 20 \\
\hline$t>111.68$ & 1 & 1 & \\
\hline & & & \\
\hline
\end{tabular}


Table S2 : Programmed times for the valve switches (Vitamin D2/D3)

\begin{tabular}{|c|c|c|c|}
\hline Time [ min] & Four-port valve position & Six-port valve position & Cycle number \\
\hline 8.35 & 1 & 1 & Transfer starts \\
\hline 9.02 & 2 & 1 & Transfer ends \\
\hline 10.33 & 1 & 1 & Recycling starts \\
\hline 10.33 & 1 & 2 & 1 \\
\hline 18.13 & 1 & 1 & 2 \\
\hline 23.50 & 1 & 2 & 3 \\
\hline 28.87 & 1 & 1 & 4 \\
\hline 34.24 & 1 & 2 & 5 \\
\hline 39.61 & 1 & 1 & 6 \\
\hline 44.98 & 1 & 2 & 7 \\
\hline 50.35 & 1 & 1 & 8 \\
\hline 55.72 & 1 & 2 & 9 \\
\hline 61.09 & 1 & 1 & 10 \\
\hline 66.46 & 1 & 2 & 11 \\
\hline 71.83 & 1 & 1 & 12 \\
\hline 77.20 & 1 & 2 & 14 \\
\hline 82.57 & 1 & 1 & Collect pure target \\
\hline$t>82.57$ & 1 & 1 & \\
\hline
\end{tabular}


Table S3 : Best estimated parameters of MMC retention model

\begin{tabular}{|c|c|c|}
\hline & $\begin{array}{c}\text { Adenosine } \\
\text { 5'-monophosphate }\end{array}$ & Procainamide \\
\hline $\mathrm{pK}_{\mathrm{a}, \mathrm{AEX}}$ & \multicolumn{2}{|c|}{8.49} \\
\hline $\mathrm{z}_{\mathrm{A}}$ & 0 & +2 \\
\hline $\mathrm{K}_{0, \mathrm{RP} / \mathrm{AEX}, \mathrm{A}}$ & 4.82 & 0 \\
\hline $\mathrm{Z}_{\mathrm{B}}$ & -1 & +1 \\
\hline $\mathrm{K}_{0, \mathrm{RP} / \mathrm{AEX}, \mathrm{B}}$ & 1.83 & $8.78 \times 10^{2}$ \\
\hline $\mathrm{Z}_{\mathrm{C}}$ & -2 & 0 \\
\hline $\mathrm{K}_{0, \mathrm{RP} / \mathrm{AEX}, \mathrm{C}}$ & $4.34 \times 10^{-2}$ & $3.46 \times 10^{3}$ \\
\hline
\end{tabular}


${ }_{273} 12$ Supplementary Figures 
Figure S1

1-Clean from early gradient eluters

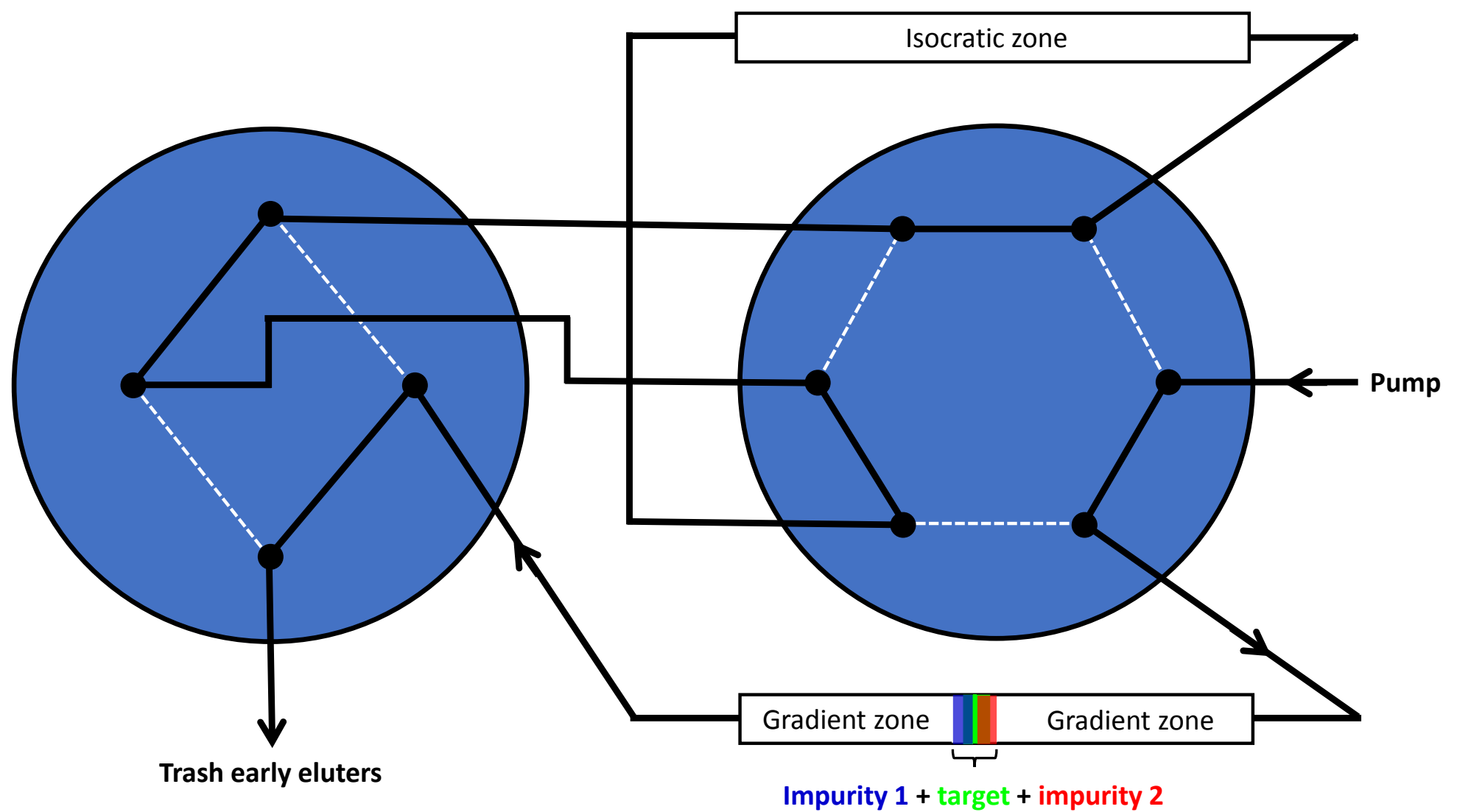


Figure S2 2-Transfer target and co-eluting impurities for recycling

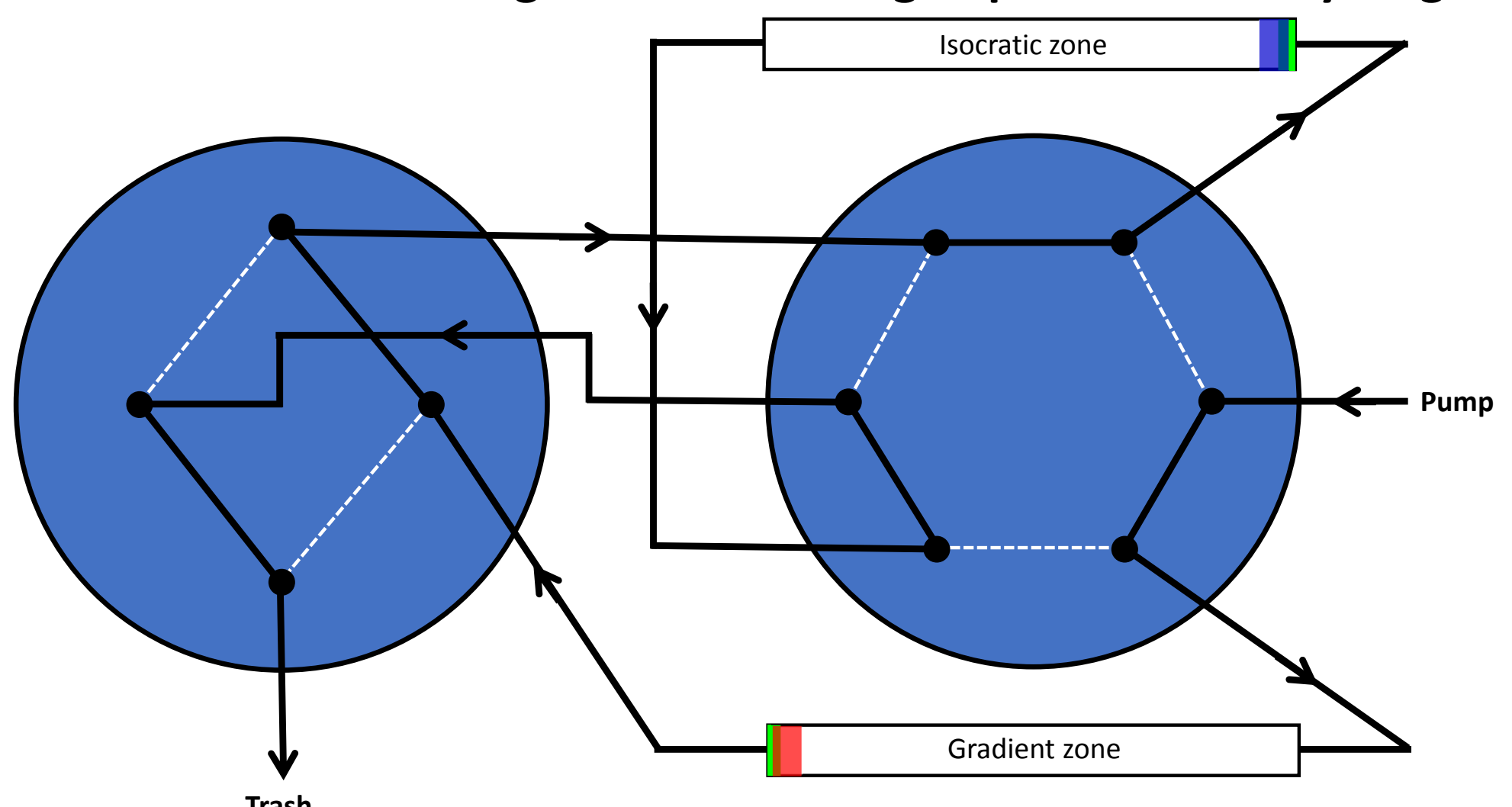

Trash 
Figure S3 3-Cleaning from late gradient eluters

Target zone parked

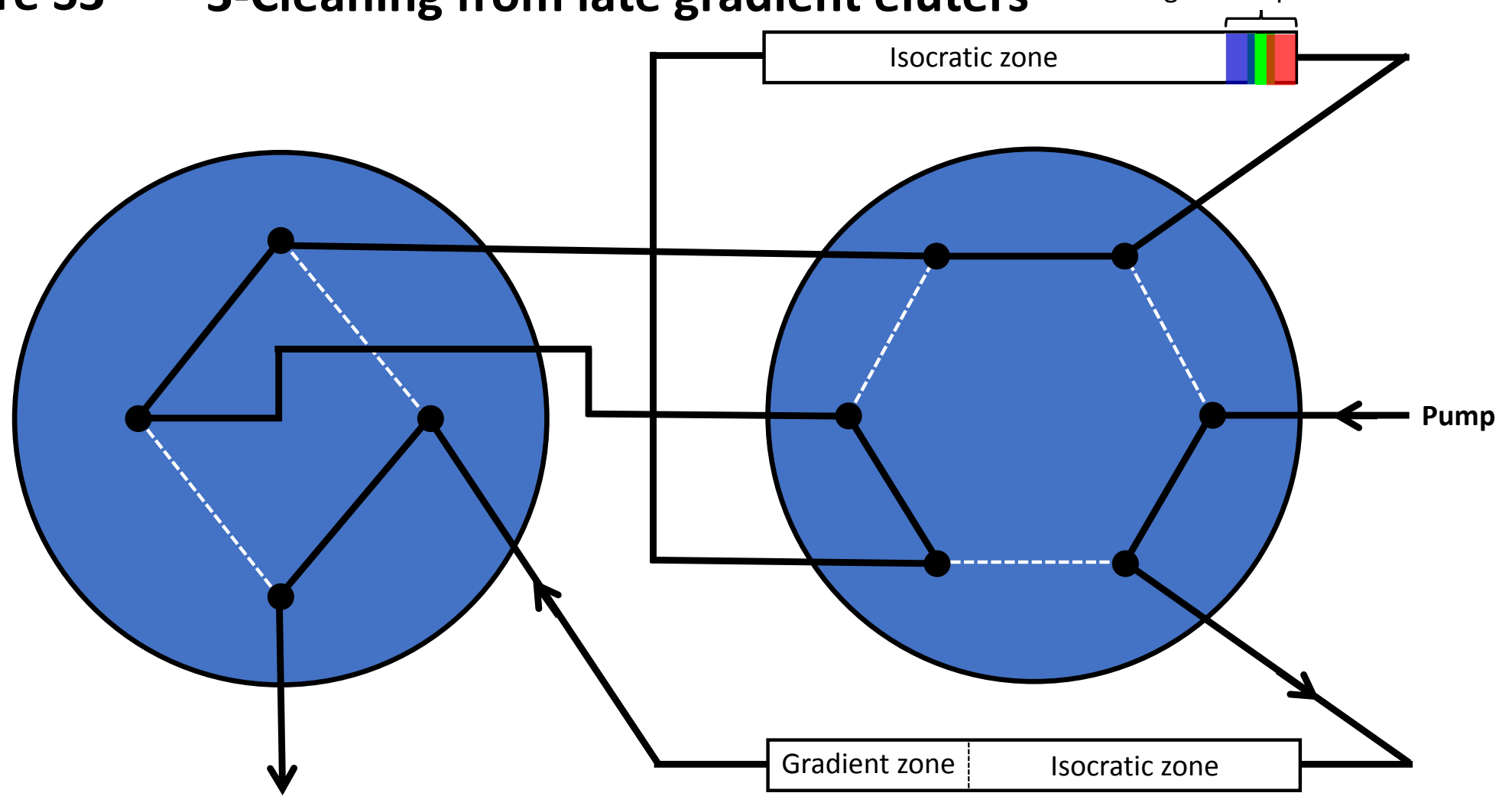

Trash 
Figure S4

\section{4-Start recycling process}

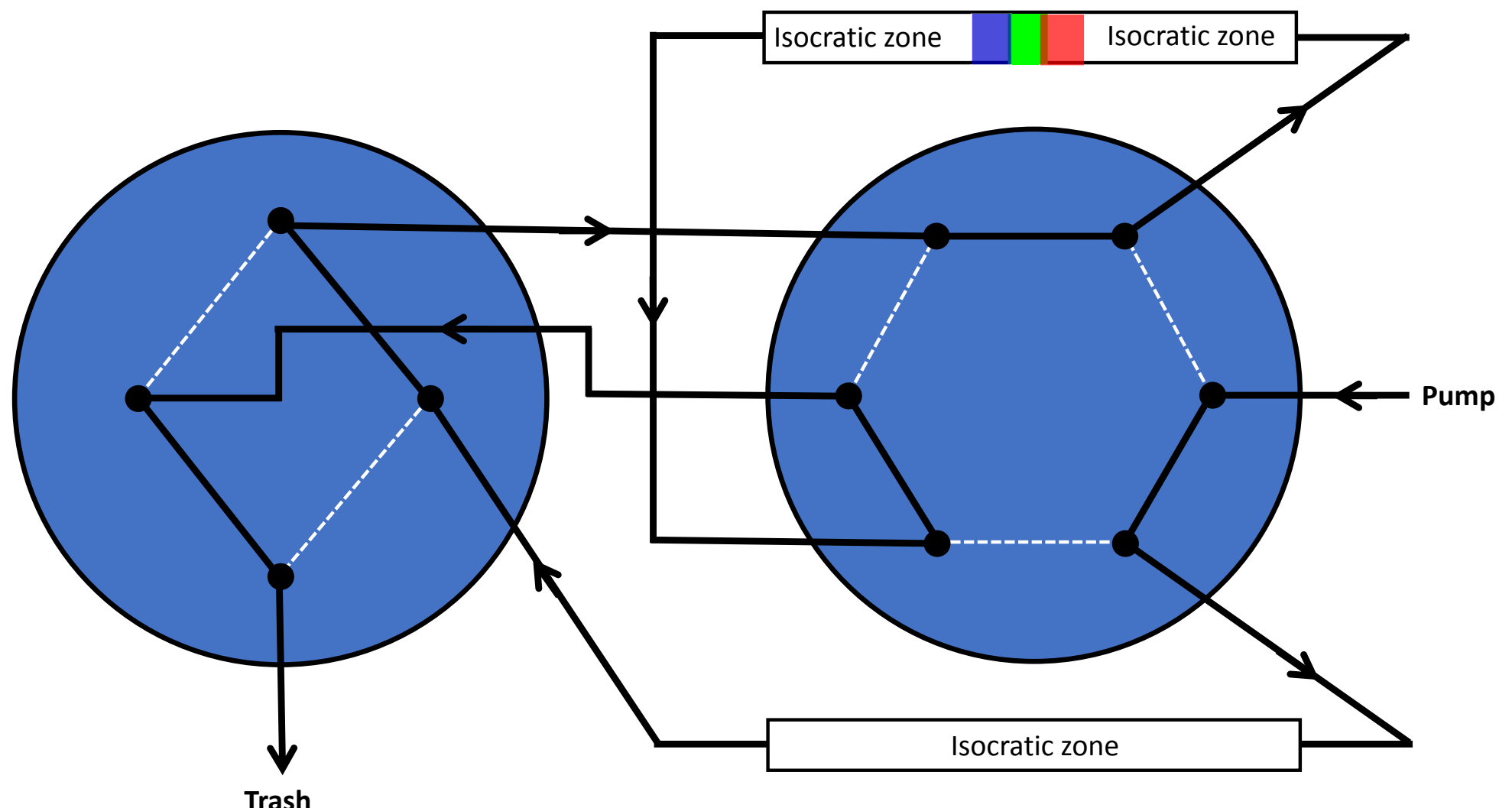


Figure S5

\section{5-Recycling process (zone transfer)}

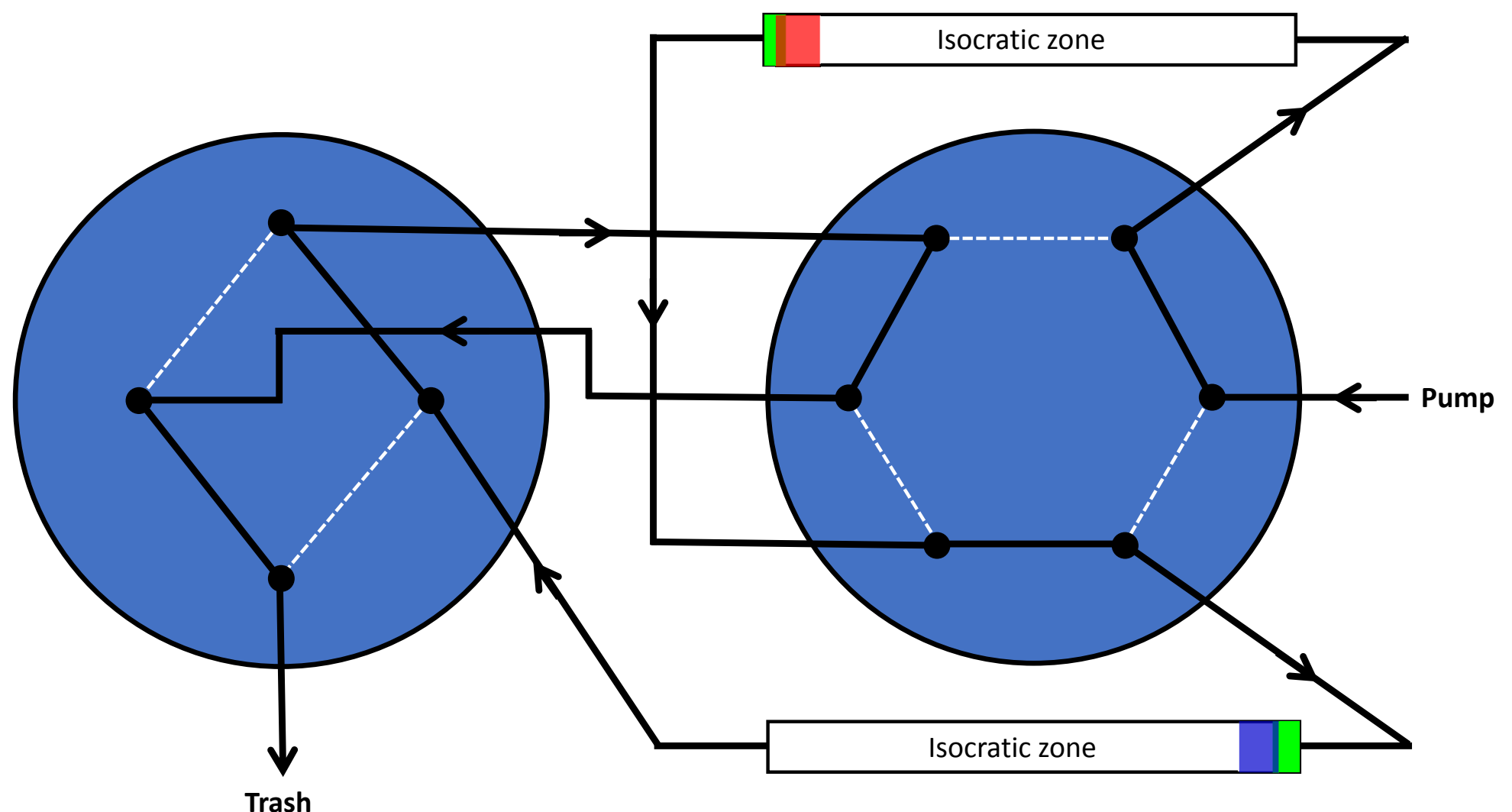


Figure S6

6-Trash first co-eluting impurity

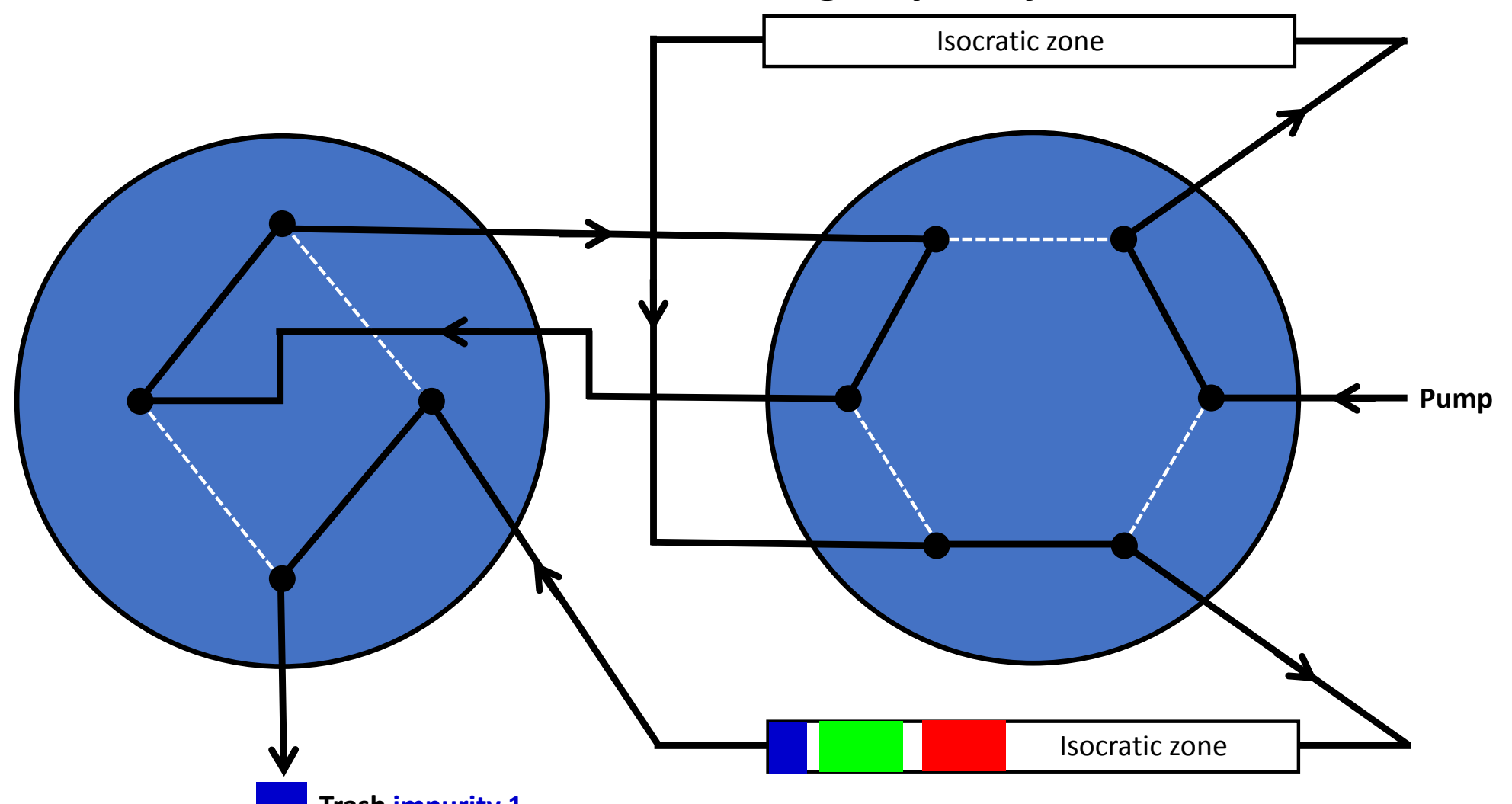

Trash impurity 1 
Figure S7

\section{7-Collect target}

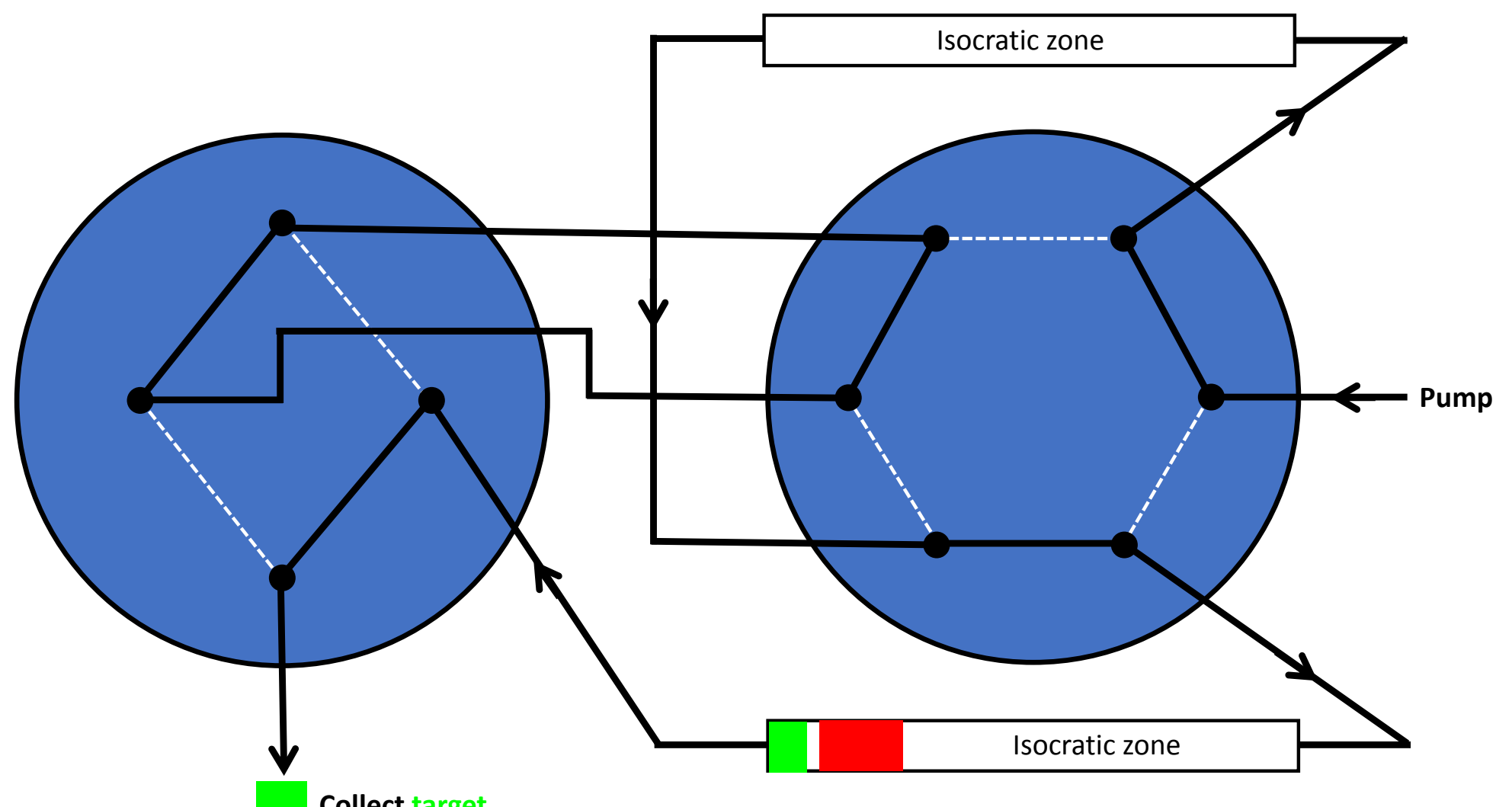

Collect target 
Figure S8

\section{8-Trash second co-eluting impurity}

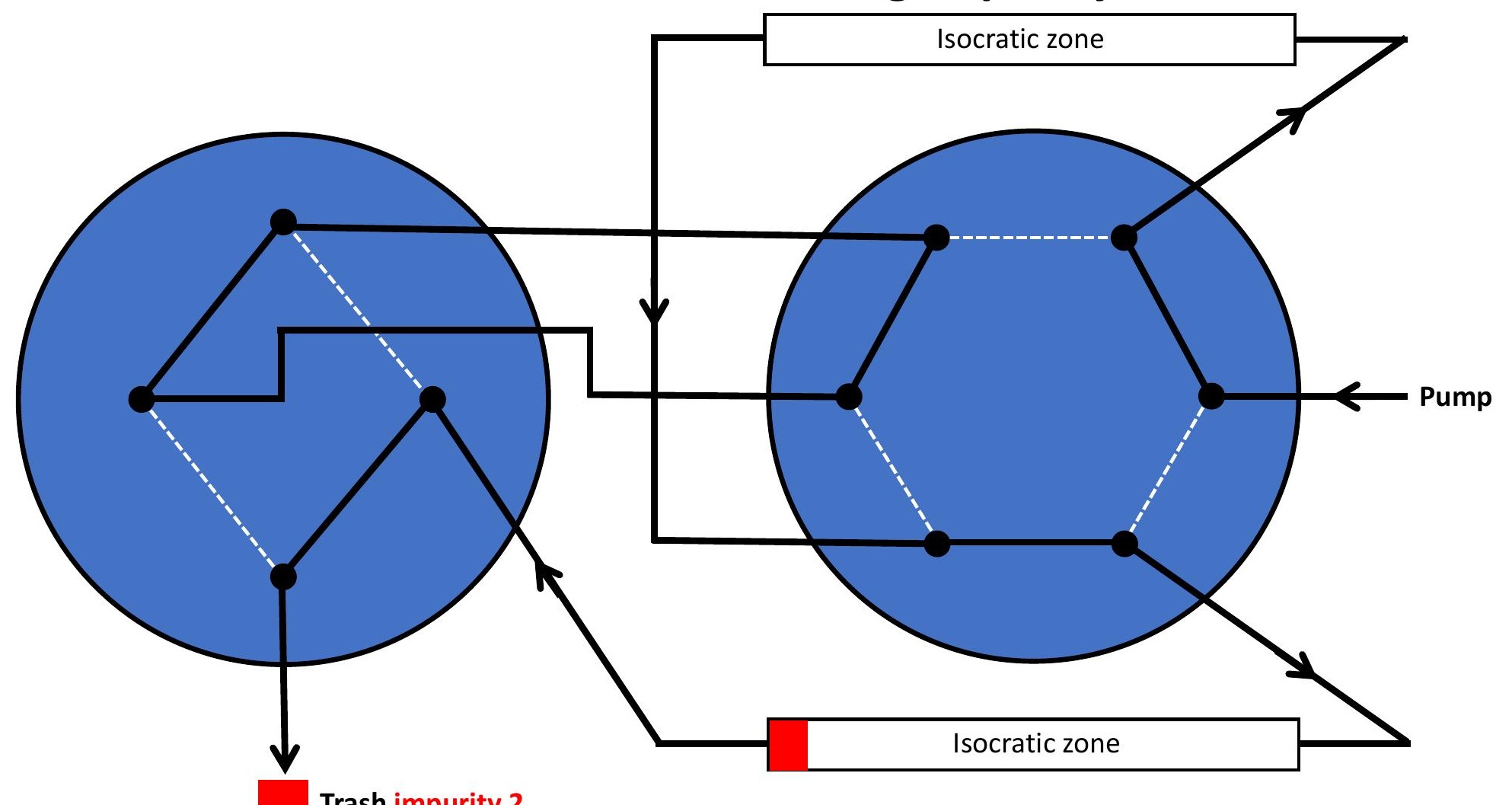

Trash impurity 2 
Figure S9

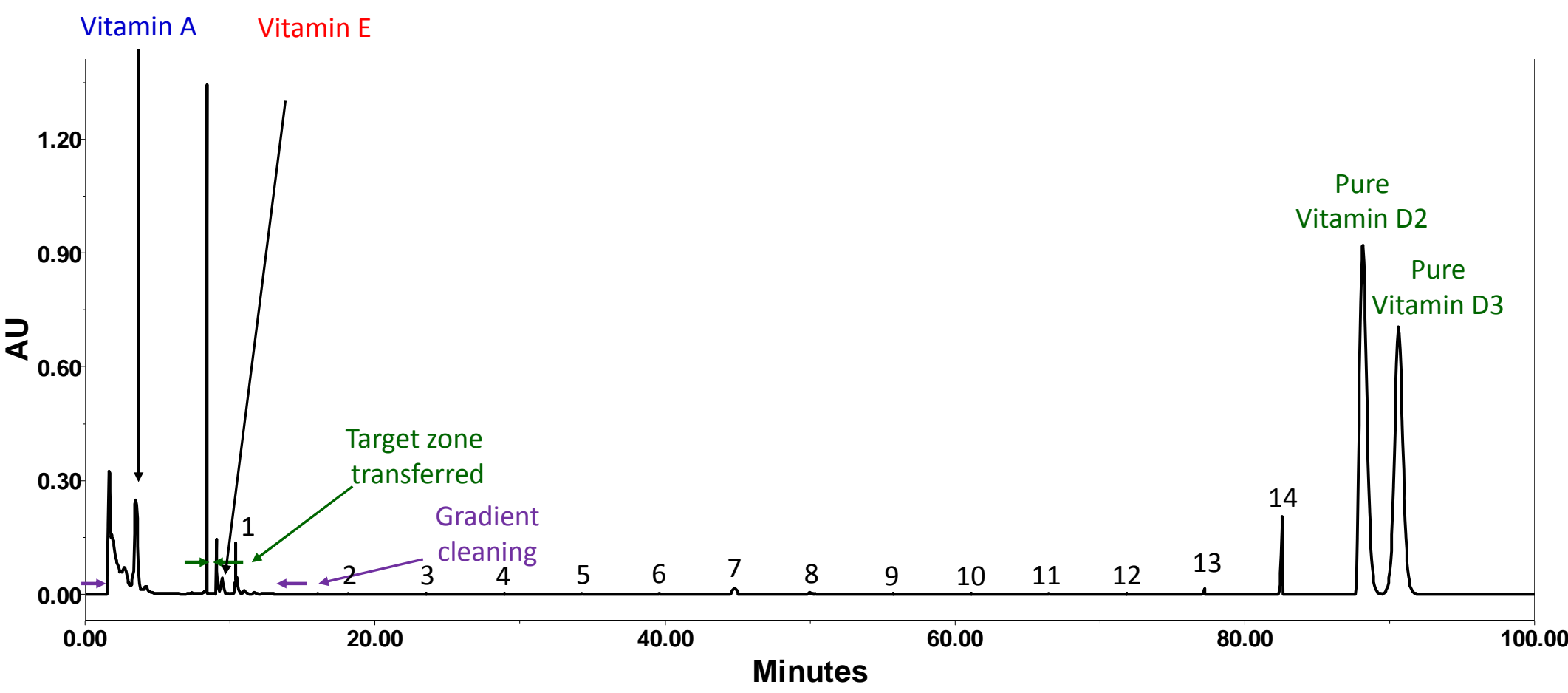


Figure S10<smiles>CCN(CC)CCNC(=O)c1ccc(N)cc1</smiles>

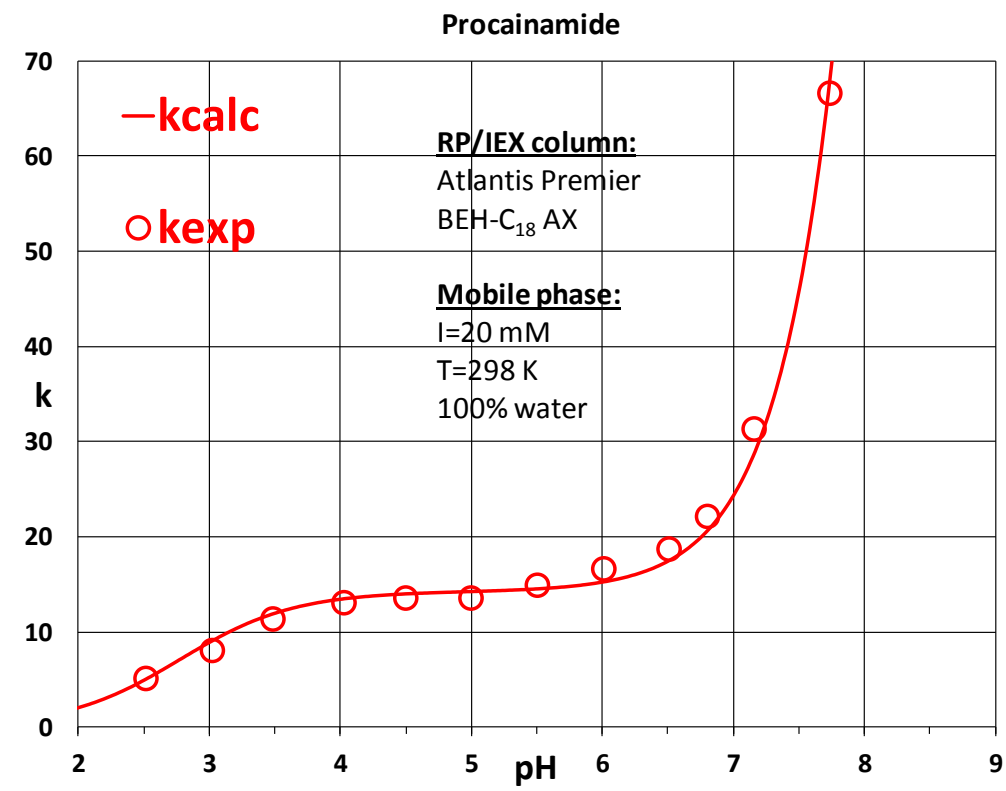


Figure S11
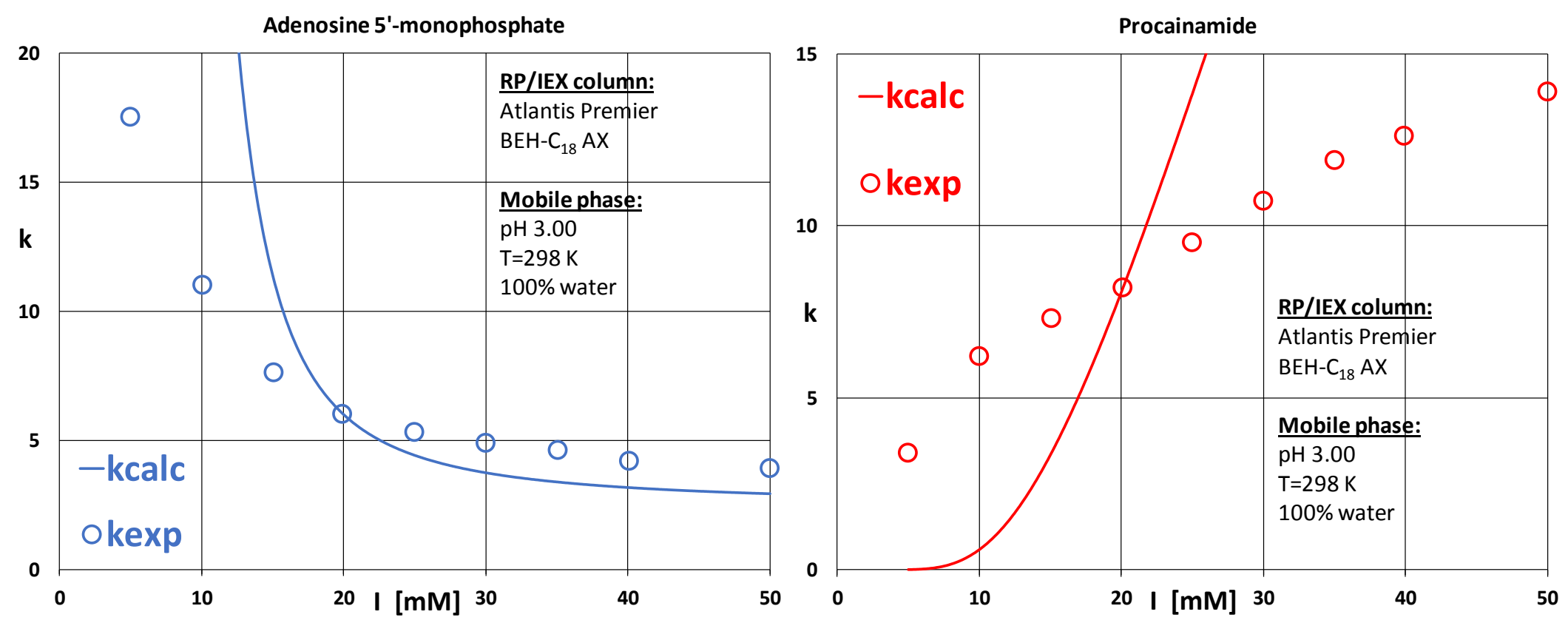
Figure S12

\section{$4.0 \mathrm{~mL} / \mathrm{min}$}

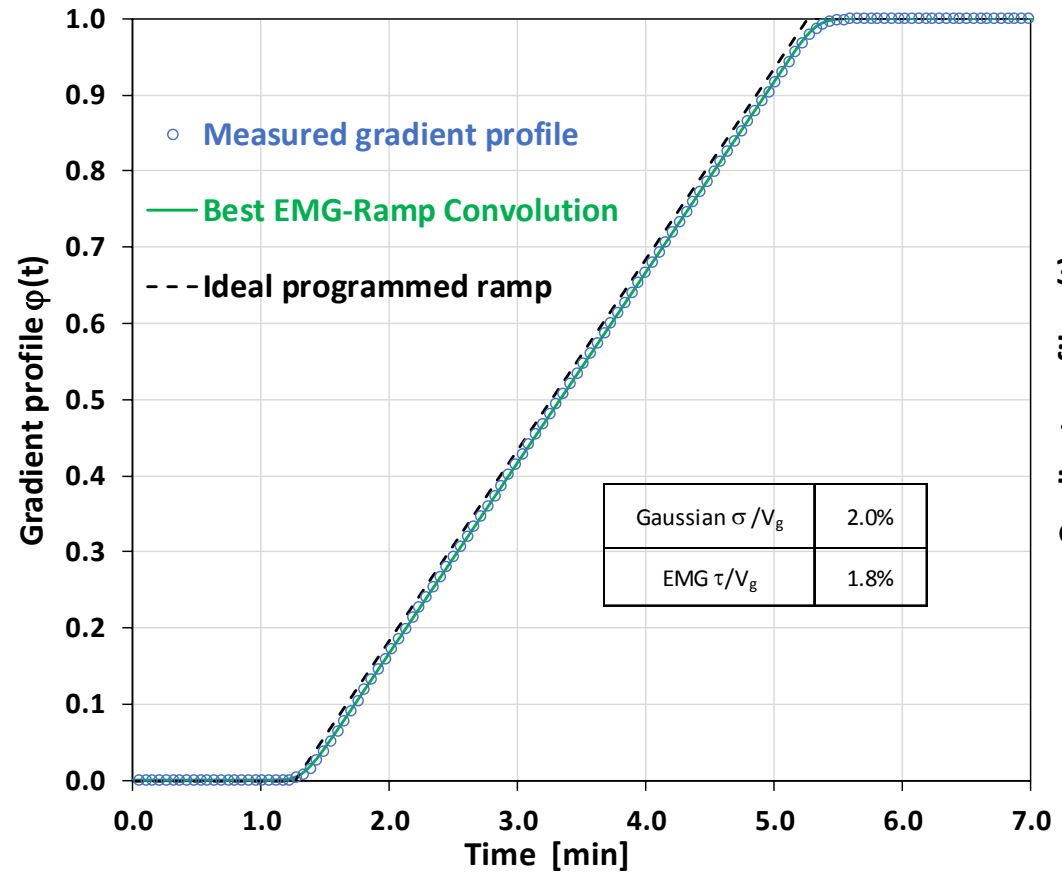

$2.0 \mathrm{~mL} / \mathrm{min}$

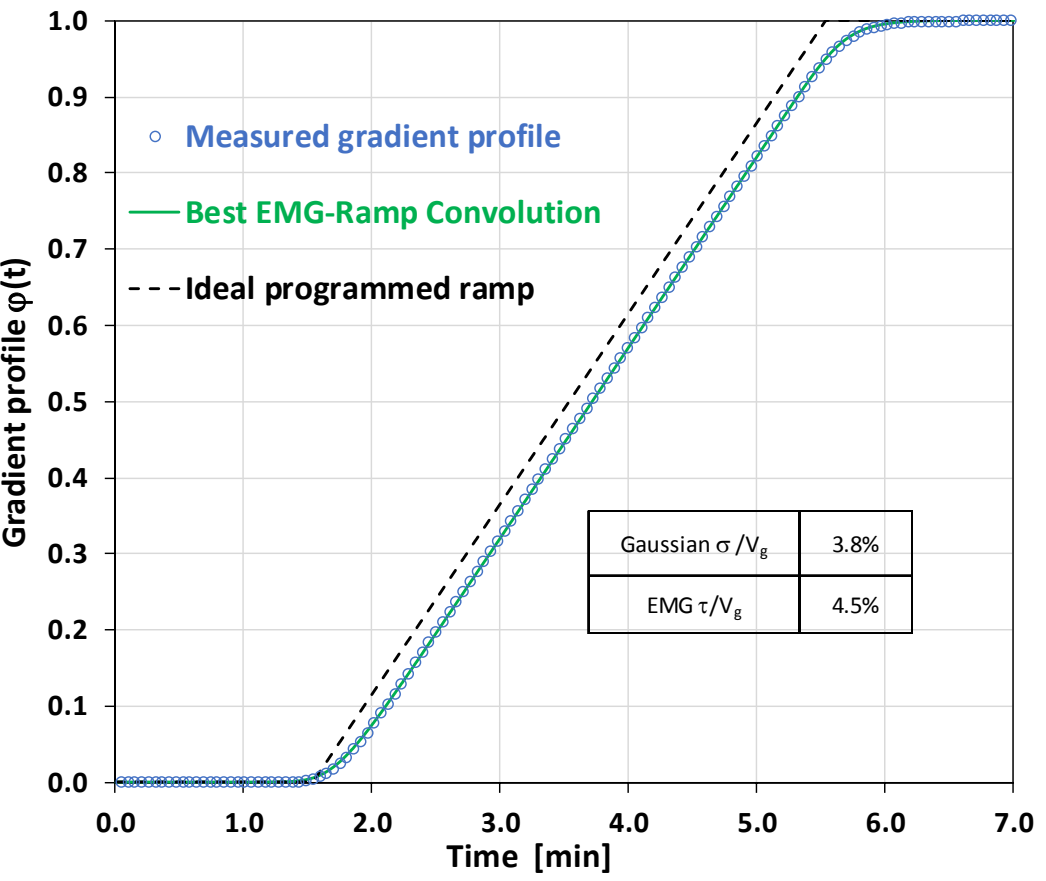


Figure S13
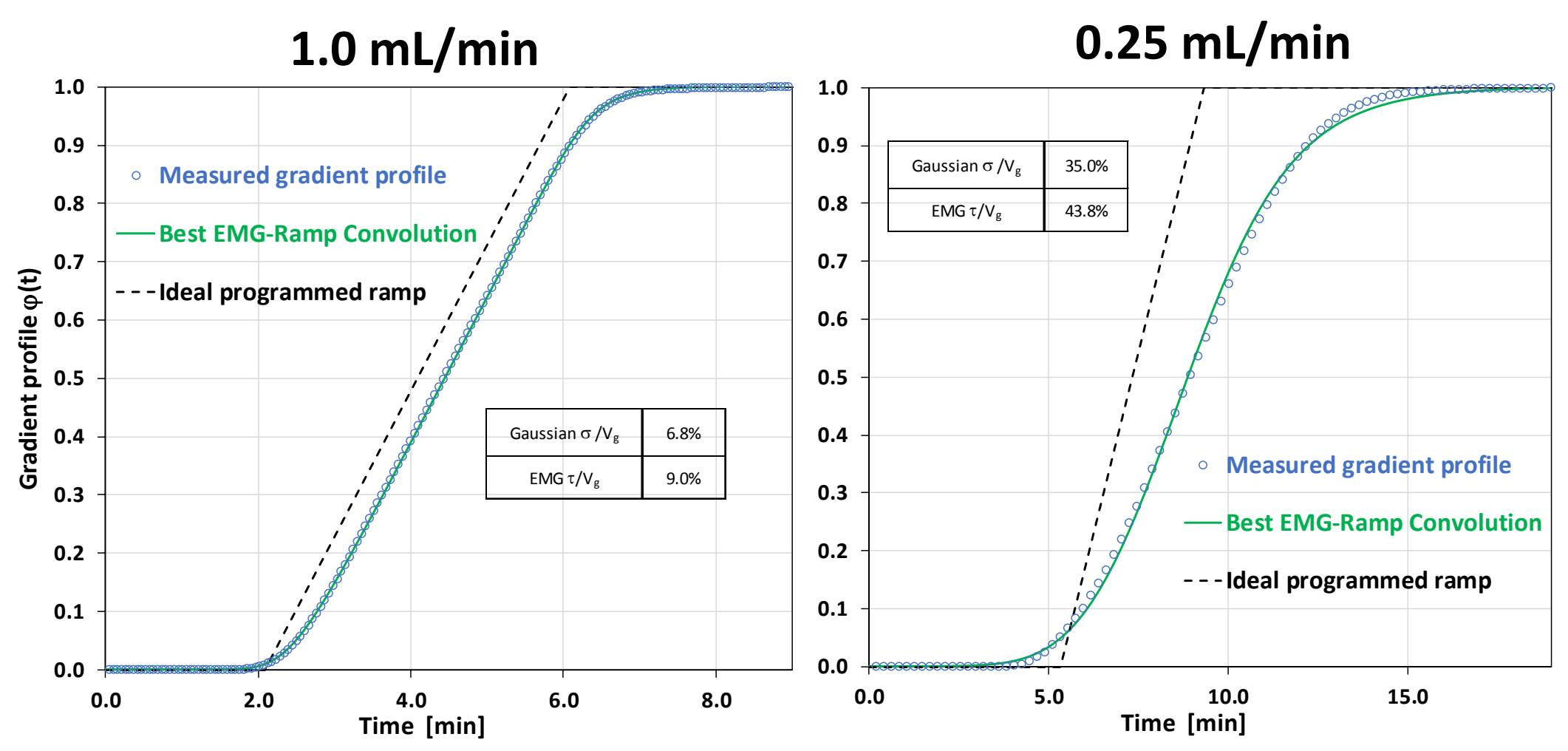


\section{References}

[1] R. Smith, C. Nieass, M. Wainwright, A review of methods for the determination of hold-up volume in modern liquid chromatography, J. Liq. Chromatogr. 9 (1986) 13871430.

[2] F. Gritti, Y. V. Kazakhevich, G. Guiochon, Measurement of hold-up volumes in reverse-phase liquid chromatography. definition and comparison between static and dynamic methods, J. Chromatogr. A 1161 (2007) 157-169.

[3] R. J. Rimmer, C. S. Simmons, J. G. Dorsey, The measurement and meaning of void volumes in reversed-phase liquid chromatography, J. Chromatogr. A 965 (2002) 219-232.

[4] U. Neue, Nonlinear retention relationships in reversed-phase chromatography, Chromatographia 63 (2006) S45-S53.

[5] U. Neue, H.-J. Kuss, Improved reversed-phase gradient retention modeling, J. Chromatogr. A 1217 (2010) 3794-3803.

[6] F. Gritti, Gradient method transfer after changing the average pore diameter ofthe chromatographic stationary phase i one-dimensionalsample mixture, J. Chromatogr. A 1597 (2019) $119-131$.

[7] F. Gritti, M. Leal, T. McDonald, M. Gilar, Ideal versus real automated twin column recycling chromatography processs, J. Chromatogr. A 1508 (2017) 81-94.

[8] F. Gritti, S. Besner, S. Cormier, M. Gilar, Applications of high-resolution recycling liquid chromatography : from small to large molecules, J. Chromatogr. A 1524 (2017) 108-120.

[9] F. Gritti, S. Cormier, Performance optimization of ultra high-resolution recycling liquidchromatography, J. Chromatogr. A 1532 (2018) 74-88.

[10] F. Gritti, M. Basile, S. Cormier, M. Fogwill, M. Gilar, T. McDonald, F. Riley, Y. Qi, Semipreparative high-resolution recycling liquid chromatography, J. Chromatogr. A 1566 (2018) $64-78$. 
[11] F. Gritti, S. Cormier, R. Morris, F. Riley, Y. Qi, Ultrahigh resolution semipreparative liquid chromatography: Application to structure elucidation of drug impurities, LC GC Europe 32(2) (2019) 62-70.

[12] L. Snyder, J. Dolan, J. Gant, Gradient elution in high-performance liquid chromatography, J. Chromatogr. 165 (1979) 3-30.

[13] P. Schoenmakers, H. A. H. Billiet, R. Tussen, L. D. Galan, Gradient selection in reversed-phase liquid chromatography, J. Chromatogr. A 149 (1978) 519-537.

[14] J. Kostka, F. Gritti, K. Kaczmarski, G. Guiochon, Modeling of thermal processes in very high pressure liquid chromatography for column immersed in a water bath: Application of the selected models, J. Chromatogr. A 1217 (2010) 4704-4712.

[15] D. Asberg, J. Samuelsson, M. Lesko, A. Cavazzini, K. Kaczmarski, T. Fornstedt, Method transfer from high-pressure liquid chromatography to ultra-high-pressure liquid chromatography. ii. temperature and pressure effects, J. Chromatogr. A 1401 (2015) 52-59.

[16] U. Neue, C. Phoebe, K. Tran, Y. Cheng, Z. Lu, Dependence of reversed-phase retention of ioniozable analytes on ph, concentration of organic solvent and silanol activity, J. Chromatogr. A 925 (2001) 49-67.

[17] U. Neue, K. V. Tran, A. Mendez, P. Carr, The combined effect of silanols and the reversedphase ligand on the retention of positively charged analytes, J. Chromatogr. A 1063 (2005) $35-45$.

[18] J. Stahlberg, I. Hagglund, Adsorption isotherm of tetrabutylammonium ion and its relation to the mechanism of ion pair chromatography, Anal. Chem. 60 (1988) 1958-1964.

[19] I. Hagglund, J. Stahlberg, The combined effect of silanols and the reversed-phase ligand on the retention of positively charged analytes, J. Chromatogr. A 2005 (2005) 35-45. 
[20] F. Kiani, H. Rahmaini, A. Bahadori, F. Koohyar, Determination of acidic dissociation constants of adenosine 5- monophosphate and guanine 5- monophosphate in water using ab initio and dft methods, Cont. J. Biol. Sci. 7 (2014) 1-29.

[21] J. Knox, R. Kaliszan, Theory of solvent disturbance peaks and experimental determination of thermodynamic dead-volume in column liquid chromatography, J. Chromatogr. 349 (1985) 211-234.

[22] Y. V. Kazakhevich, H. M. McNair, Thermodynamic definition of hplc dead volume, J. Chromatogr. Sci. 31 (1993) 317-322.

[23] Y. V. Kazakhevich, H. M. McNair, Study of the excess adsorption of the eluent components on different reversed-phase adsorbents, J. Chromatogr. Sci. 33 (1995) 321-327.

[24] F. Gritti, G. Guiochon, Thermodynamics of adsorption of binary aqueous organic liquid mixtures on a rplc adsorbent, J. Chromatogr. A 1155 (2007) 85-99.

[25] F. Gritti, G. Guiochon, The distortion of gradient profiles in reversed-phase liquid chromatography, J. Chromatogr. A 1340 (2014) 50-58.

[26] F. Gritti, G. Guiochon, Separations by gradient elution: Why are steep gradient profiles distorted and what is their impact on resolution in reversed-phase liquid chromatography, J. Chromatogr. A 1344 (2014) 66-75.

[27] F. Gritti, G. Guiochon, Calculated and experimental chromatograms for distorted gradients and non-linear solvation strength retention models, J. Chromatogr. A 1356 (2014) 96-104.

[28] A. Felinger, Data Analysis and Signal Processing in Chromatography, In: Data handling in science and technology - Volume 21, Elsevier, Amsterdam, 1998.

[29] A. Wang, L. C. Tan, P. W. Carr, Comparative study of the linear solvation energy relationship, linear solvent strength theory, and typical-conditions model for retention prediction in reversedphase liquid chromatography, J. Chromatogr. A 848 (1999) 21-37. 
[30] A. Wang, P. W. Carr, Global linear solvation energy relationships for retention prediction in reversed-phase liquid chromatography, J. Chromatogr. A 965 (2002) 3-23.

[31] J. Rybka, A. Höltzel, S. Melnikov, A. Seidel-Morgenstern, U. Tallarek, A new view on surface diffusion from molecular dynamics simulations of solute mobility at chromatographic interfaces, Fluid Phase Equilibria 407 (2016) 177-187.

[32] D. W. Sindorf, G. E. Maciel, Silicon-29 nmr study of dehydrated/rehydrated silica gel using cross polarization and magic-angle spinning, J. Am. Chem. Soc. 105 (1983) 1487-1493.

[33] D. W. Sindorf, G. E. Maciel, Silicon-29 nuclear magnetic resonance study of hydroxyl sites on dehydrated silica gel surfaces, using silylation as a probe, J. Phys. Chem. 87 (1983) 5516-5521.

[34] G. E. Maciel, Silica Surfaces: Characterization, In: Encyclopedia of Magnetic Resonance, John Wiley \& Sons, Ltd, 2007.

[35] R. Cheng, X. Liu, Y. Fang, M. Terano, B. Liu, High-resolution 29si cp/mas solid state nmr spectroscopy and dft investigation on the role of geminal and single silanols in grafting chromium species over phillips cr/silica catalyst, Applied Catalysis A, General 543 (2017) $26-33$.

[36] M. G. Martin, J. I. Siepmann, Transferable potentials for phase equilibria. 1. united-atom description of n-alkanes, J. Phys. Chem. C 102 (1998) 2569-2577.

[37] M. G. Martin, J. I. Siepmann, Novel configurational-bias monte carlo method for branched molecules. transferable potentials for phase equilibria. 2. united-atom description of branched alkanes, J. Phys. Chem. C 103 (1999) 4508-4517.

[38] J. M. Stubbs, J. J. P. J. I. Siepmann, Molecular dynamics simulation of wateracetonitrile mixtures in a silica slit, J. Phys. Chem. C 108 (2004) 17596-17605.

[39] R. D. Mountain, Microstructure and hydrogen bonding in wateracetonitrile mixtures, J. Phys. Chem. B 114 (2010) 16460-16464. 
[40] R. D. Mountain, Molecular dynamics simulation of wateracetonitrile mixtures in a silica slit, J. Phys. Chem. C 117 (2013) 3923-3929.

[41] T. S. Gulmen, W. H. Thompson, Testing a two-state model of nanoconfined liquids: Conformational equilibrium of ethylene glycol in amorphous silica pores, Langmuir 22 (2006) 10919-10923.

[42] M. Svard, A. C. Rasmuson, Force fields and point charges for crystal structure modeling, Ind. Eng. Chem. Res. 48 (2009) 2899-2912.

[43] J. Rybka, A. Höltzel, U. Tallarek, Surface diffusion of aromatic hydrocarbon analytes in reversed-phase liquid chromatography, J. Phys. Chem. C 121 (2017) 17907-17920. 